\title{
More hospital doctors are opting to retire early
}

\author{
Tom Moberly UK editor
}

The BMJ

Hospital doctors in England and Wales are increasingly choosing to take early retirement, show figures released to The $B M J$ by the NHS Business Services Authority.

The number of hospital doctors claiming their NHS pension on grounds of voluntary early retirement rose from 164 in 2008 to 397 in 2018 (fig 1). The number retiring on ill health grounds rose from 12 to 79 over the same period.

A greater proportion of doctors claiming their pensions now do so on health grounds or are taking voluntary early retirement. In $2008,14 \%$ of hospital doctors claiming their NHS pension took voluntary early retirement; in 2018, 27\% of doctors did so. In $2008,1 \%$ retired on grounds of ill health; in $2018,5 \%$ did.

The total number of hospital doctors choosing to take their pension (whether on grounds of age, voluntary early retirement, or ill health) rose by $22 \%$ from 1205 in 2008 to 1475 in 2018 . The total number of hospital doctors working in the NHS rose by $21 \%$ over the same period, and the proportion of doctors choosing to retire was $1.25 \%$ in 2008 and $1.27 \%$ in 2018.

In March The BMJ reported on figures from the NHS Business Services Authority showing that GPs were also increasingly choosing to take early retirement. ${ }^{1}$ The number of GPs claiming their NHS pension on grounds of voluntary early retirement increased from 198 in 2007-08 to 721 in 2016-17, and the number retiring on ill health grounds rose from 12 to 63 over the same period. The number retiring on age grounds fell from 944 in 2007-08 to 380 in 2016-17.

The NHS Business Services Authority provided the data on hospital doctor retirement to $T h e B M J$ in response to a freedom of information request.

Moberly T. Rise in GPs taking early retirement. BMJ 2018;360:k1367. 10.1136/bmj.k1367 29599207

Published by the BMJ Publishing Group Limited. For permission to use (where not already granted under a licence) please go to http://group.bmj.com/group/rights-licensing/ permissions 


\section{Figure}
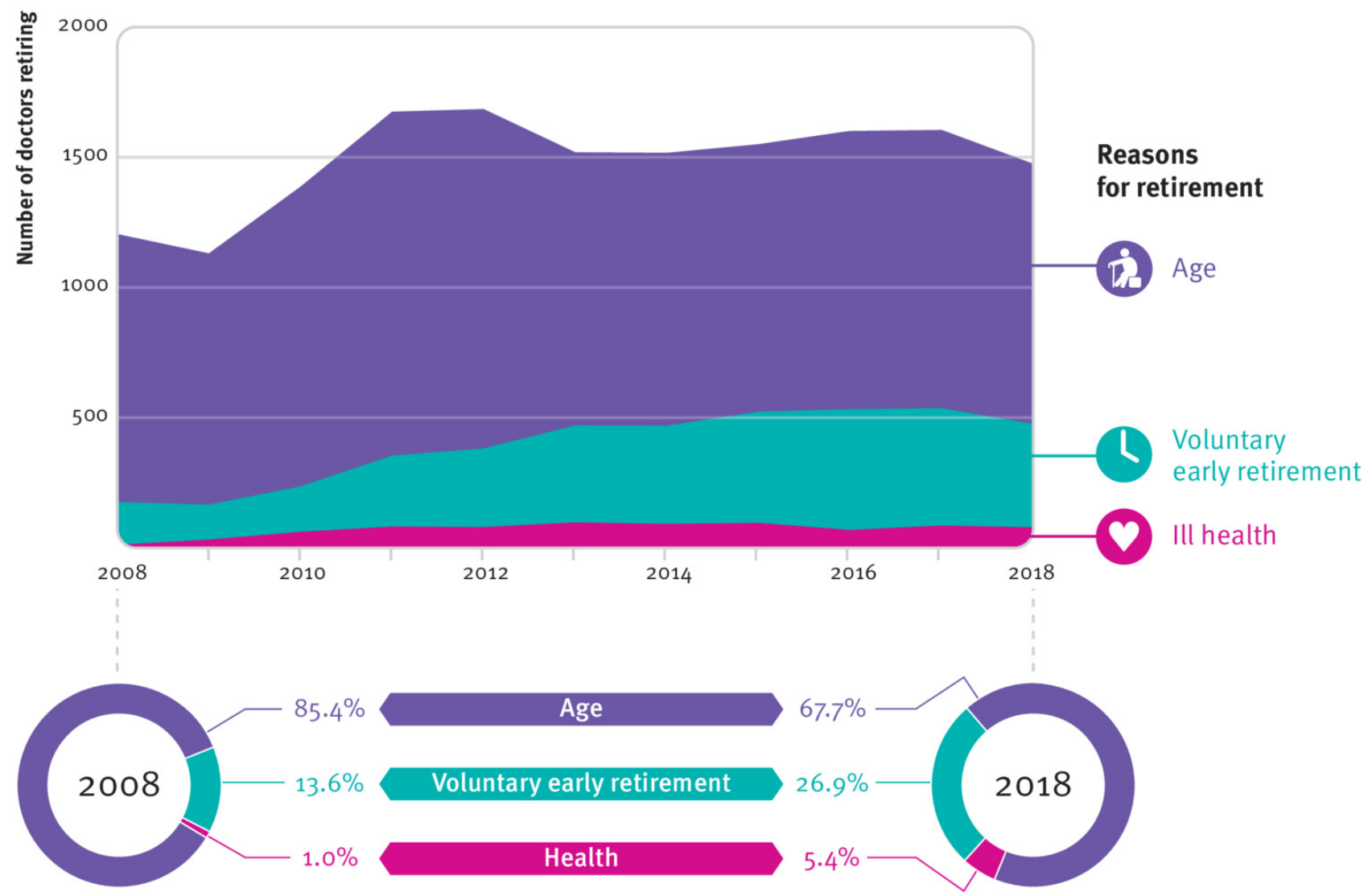

Fig 1 Number of hospital doctors retiring and reasons for retirement 